\title{
Associations Between Primary Care Provider Shortage Areas and County-Level COVID-19 Infection and Mortality Rates in the USA
}

J Gen Intern Med 35(11):3404-5

DOI: $10.1007 / \mathrm{s} 11606-020-06130-4$

(c) Society of General Internal Medicine 2020

\section{INTRODUCTION}

As COVID-19 disproportionately impacts certain regions across the USA, there have been speculations on various factors that may contribute to this disparity. ${ }^{1}$ Primary care Health Professional Shortage Areas (HPSAs) are regions with a lack of primary care providers based on need for care. These areas have been associated with greater poverty, larger proportions of racial minorities, ${ }^{2}$ low-wage essential workers, and congregate settings, including homeless shelters and prisons, all of whom could be at increased risk of contracting the virus. ${ }^{1}$ Shortage areas may also have limited availability of testing and treatment, which may contribute to higher COVID-19 mortality. ${ }^{1}$ However, it is not known whether shortage areas are associated with higher COVID-19 infection or mortality rates. This study investigates the hypothesis that primary care HPSAs are associated with higher rates of COVID-19 infection and mortality.

\section{METHODS}

County-level COVID-19 daily new cases and deaths from March 22, 2020, to May 16, 2020, in the USA were extracted from https://coronavirus.1point3acres.com/en and COVID-19 Data Repository by the Johns Hopkins University Center for Systems Science and Engineering population-based datasets on May 18, 2020. Cases and deaths were aggregated by county into weeks and only counties with reported COVID19 cases and deaths during all 8 weeks were included so that all counties were proportionately represented. 10,328 countyweeks were linked to county-level characteristics including 2019 population estimates from the US Census Bureau. ${ }^{3}$ Socioeconomic variables including poverty, unemployment, low educational attainment, population ages 65 and older, male gender, and non-Hispanic white race/ethnicity were derived from the 2017 American Community Survey

Received July 1, 2020

Accepted August 10, 2020

Published online August 21, 2020 5-year estimates. ${ }^{3}$ The 2013 rural-urban continuum codes used to classify rurality and whole county primary care HPSAs were separately derived from the 2018 Area Health Resource File. ${ }^{4}$ Primary care HPSAs were based on ratios of primary care specialties (general or family practice, general internal medicine, pediatrics, and obstetrics and gynecology) to residents depending on needs for primary care services in specific geographic areas. ${ }^{4}$

Because most counties still do not have COVID-19 testing available, counties without any reported infections may lack cases due to a lack of local testing capacity. ${ }^{5}$ Therefore, we focused on infection rates for the 10,328 county-weeks with reported COVID-19 infections as a proxy for infection burden. Generalized linear mixed models with negative binomial distribution were used to test the associations of primary care HPSAs and COVID-19 rates, controlling for time, rurality, population, and six county-level socioeconomic variables.

\section{RESULTS}

During this study period, 1,381,197 individuals were diagnosed with COVID-19 in the USA, and 85,097 died from this condition. There were $170(13.2 \%)$ whole county primary care HPSAs and $1121(86.8 \%)$ areas that were not whole county primary care HPSAs.

COVID-19 infection and death rates were higher in whole county primary care HPSAs compared with non-whole county primary care HPSAs (overall median: 30.9 vs 18.0 per 10,000 residents and 1.1 vs 0.7 per 10,000 residents, respectively). In models adjusting for county-level factors and sociodemographic characteristics shown in Table 1, primary care HPSAs were significantly associated with COVID19 infection rate (adjusted IRR: 1.41 [95\% CI, 1.19-1.66]; $p<$ 0.001 ) and COVID-19 mortality rate (adjusted IRR: 1.54 [95\% CI, 1.17-2.02]; $p=0.002$ ).

\section{DISCUSSION}

Our findings suggest that primary care provider shortage areas with reported COVID-19 cases face a higher burden of COVID-19 infections and death even after adjusting for socioeconomic and other county-level factors. While it is not possible to assess causal pathways using these cross-sectional, 
Table 1 Relationships Between Population Characteristics and COVID-19 Infection and Mortality Rates

\begin{tabular}{|c|c|c|c|c|c|c|c|c|}
\hline \multirow[b]{2}{*}{$\begin{array}{l}\text { Population } \\
\text { characteristic }\end{array}$} & \multicolumn{2}{|l|}{ Model $A^{1}$} & \multicolumn{2}{|l|}{ Model B $^{2}$} & \multicolumn{2}{|l|}{ Model $\mathbf{C}^{3}$} & \multicolumn{2}{|l|}{ Model $D^{4}$} \\
\hline & $\begin{array}{l}\text { Unadjusted IRR } \\
\text { (95\% CI) }\end{array}$ & $p$ & $\begin{array}{l}\text { Adjusted IRR } \\
\text { (95\% CI) }\end{array}$ & $p$ & $\begin{array}{l}\text { Unadjusted IRR } \\
(95 \% \text { CI) }\end{array}$ & $p$ & $\begin{array}{l}\text { Adjusted IRR } \\
(\mathbf{9 5 \%} \text { CI) }\end{array}$ & $p$ \\
\hline Primary care HPSA & $1.59(1.35-1.87)$ & $<0.001$ & $1.41(1.19-1.66)$ & $<0.001$ & $1.61(1.25-2.08)$ & $<0.001$ & $1.54(1.17-2.02)$ & 0.002 \\
\hline RUCC & $1.01(0.99-1.04)$ & 0.363 & $1.02(0.98-1.05)$ & 0.342 & $1.00(0.96-1.04)$ & 0.847 & $0.98(0.93-1.04)$ & 0.555 \\
\hline $\begin{array}{l}\text { Low Educational } \\
\text { Attainment }(\%)\end{array}$ & $1.03(1.02-1.04)$ & $<0.001$ & $1.01(1.02-0.99)$ & 0.220 & $1.03(1.01-1.05)$ & $<0.001$ & $0.99(0.97-1.01)$ & 0.426 \\
\hline Unemployment (\%) & $1.15(1.10-1.21)$ & $<0.001$ & $1.04(0.98-1.09)$ & 0.216 & $1.23(1.15-1.32)$ & $<0.001$ & $1.08(0.99-1.18)$ & 0.078 \\
\hline Poverty (\%) & $1.03(1.02-1.04)$ & $<0.001$ & $0.99(0.97-1.00)$ & 0.141 & $1.04(1.02-1.06)$ & $<0.001$ & $1.00(0.97-1.03)$ & 0.914 \\
\hline Male gender (\%) & $0.97(0.94-1.01)$ & 0.099 & $0.98(0.95-1.01)$ & 0.232 & $0.89(0.85-0.94)$ & $<0.001$ & $0.94(0.89-1.00)$ & 0.039 \\
\hline $\begin{array}{l}\text { Population ages } \\
65 \text { and older }(\%)\end{array}$ & $0.97(0.96-0.99)$ & $<0.001$ & $0.99(0.97-1.00)$ & 0.179 & $1.01(0.99-1.03)$ & 0.513 & $1.04(1.01-1.06)$ & 0.003 \\
\hline $\begin{array}{l}\text { Non-Hispanic white } \\
\text { population }(\%)\end{array}$ & $0.99(0.98-0.99)$ & $<0.001$ & $0.99(0.98-0.99)$ & $<0.001$ & $0.98(0.98-0.99)$ & $<0.001$ & $0.99(0.98-0.99)$ & $<0.001$ \\
\hline
\end{tabular}

${ }^{1}$ Model A individually assessed the association between each characteristic and COVID-19 confirmed case rates

${ }^{2}$ Model B mutually adjusted for all population characteristics and COVID-19 confirmed case rates

${ }^{3}$ Model $C$ individually assessed the association between each characteristic and COVID-19 mortality rates

${ }^{4}$ Model D mutually adjusted for all population characteristics and confirmed COVID-19 mortality rates

HPSAs, Health Professional Shortage Areas; IRR, incidence rate ratio; RUCC, rural-urban continuum codes; Low Educational Attainment (\%), the percentage with less than high school educational attainment among the population ages 25 and older; Unemployment (\%), percentage of unemployment among civilian labor force population 16 years and over; Poverty (\%), percentage of families and people whose income in the past 12 months is below the poverty level

observational data, it is possible that reduced access to primary care in provider shortage areas could lead to higher burden of COVID-19 disease and death rates due to delays in diagnosis and resource shortages. It is also possible that these areas face other, unmeasured medical, economic, and social makers of vulnerability. ${ }^{2}$ Further research should track these findings over time and seek to disaggregate the possible underlying mechanisms. Regardless of the causal pathway, the findings suggest that many communities are likely to face simultaneous challenges of high burden of coronavirus, social and economic disadvantage, and limited access to primary medical care.

Benson S. Ku, M.D. ${ }^{1}$

Benjamin G. Druss, M.D., M.P.H. ${ }^{2}$

${ }^{1}$ Department of Psychiatry and Behavioral Sciences, Emory University School of Medicine,

Atlanta, GA, USA

${ }^{2}$ Department of Health Policy and Management, Rollins School of Public Health, Emory University, Atlanta, GA, USA
Corresponding Author: Benson S. Ku, M.D.; Department of Psychiatry and Behavioral Sciences, Emory University School of Medicine, Atlanta, GA, USA (e-mail: bsku@emory.edu).

\section{Compliance with Ethical Standards:}

Conflict of Interest: The authors declare that they do not have a conflict of interest.

\section{REFERENCES}

1. Bibbins-Domingo $\mathbf{K}$. This time must be different: disparities during the COVID-19 pandemic. Ann Intern Med. April 2020. https://doi.org/10. 7326/M20-2247

2. Streeter RA, Snyder JE, Kepley H, Stahl AL, Li T, Washko MM. The geographic alignment of primary care Health Professional Shortage Areas with markers for social determinants of health. PLaS One. 2020;15(4). https://doi.org/10.1371/journal.pone.0231443

3. US Census Bureau. Census.gov. Accessed 30 Mar 2020.

4. Health Resources and Services. Area Health Resources Files. https://data. hrsa.gov/topics/health-workforce/ahrf. Accessed 30 March 2020.

5. Castlight. Location, location, location. https://www.castlighthealth.com/ wp-content/uploads/2020/05/Retail-Clinics-COVID19-Report.pdf. Accessed 22 May 2020.

Publisher's Note: Springer Nature remains neutral with regard to jurisdictional claims in published maps and institutional affiliations. 